dition the entire coast line from Keppel Point to McFarlane Harbour was traversed on foot.

Perhaps no branch of anthropology has been more cultivated or yielded larger results during the last few years than that relating to prehistoric man. At the same time no inconsiderable part of the evidence has been derived from the examination of osseous and other remains in caves both in England and on the continent. The greatest interest has always been felt in the revelations that might accrue to the science of anthropology by an investigation of the bone-caves of Borneo, situated as that island is on the confines of the lost continent Lemuria, where Dr. Peschel thinks it possible that the first appearance of man may have taken place. In his late presidential address to the Anthropological Institute, Mr. Evans referred to the fact that Mr. Everett, a well-known naturalist, had undertaken to devote a twelvemonth to the prosecution of cave-researches in Borneo. Mr. Everett commenced his researches in October last, and the principal proceeds from more or less extensive excavations in several caves are now on their way to this country. Mr. Everett's first quarterly report had just been received by Mr. Evans, in which the discovery is reported of numerous mammalian remains, the age of which has still, of course, to be determined, and also of remains of a race of men of whom no local tradition seems to be extant, and who habitually used the caves of Upper Saráwak either as domiciles, or as places of sepulture, or possibly for other purposes. Though unknown to history or tradition, this race of men appear to have been acquainted with the use of manufactured iron, so that, probably, no great antiquity is to be assigned to the remains already discovered. Mr. Evans stated that at least $100 l$. has still to be forthcoming for the exploration fund, in addition to what has been already subscribed, and that he would be happy to receive subscriptions.

THE magnetic behaviour of iron in the form of powder has lately been investigated by Prof. von Waltenhofen, of Prague. Three samples of finely pulverised and chemically pure iron, filling well-closed glass tubes, were magnetised by means of spirals of wire, through which were sent currents of increasing intensity, and the magnetic moments thus produced were measured. A comparison of these with those excited in equally heavy iron and steel bars by equal magnetising forces shows that the specific magnetisability of pulverised iron is not only much smaller than that of coherent iron, but even smaller than that of the hardest kind of steel known, viz., glass-hard Wolfram steel. Prof, Waltenhofen seeks an explanation of this in the circumstance that the magnetic mutual action of the polar molecules, which strengthens the action of exterior magnetising forces, is greatly lessened through the comparatively great intervals between the particles of the powdered iron; and the numbers he obtained led him to the conclusion that the electromagnetism of an iron bar is to be regarded only in the least part as due to direct action of the magnetising current, and mainly due to that reciprocal action of the molecular magnets.

IN his ninth Bridgewater treatise, Mr. Babbage refers to the possibility of constructing an automaton which would play the simple game of tit-tat-to (or "oughts and crosses"). Such a machine (probably the first ever constructed), working on the principle of a mechanical table, has been made by Mr. Freeland of Philadelphia. It is described in the January number of the Fournal of the Franklin Institute, and was exhibited at the Institute on October 16 last year. It is now at the University of Pennsylvania, where, since its final adjustment, it has played a large number of games without losing a single one.

EARTHQUAKES are reported from Waldkirch and Buchholz, in Baden, on January 26, at 10 P.M. Both villages are situated in the Elz Valley, on the slopes of the Kandel Mountain, which measures 1,380 metres in height. A violent shock was also felt in the Swiss Canton of Uri on January 24, at 2 A.M.

THE Italian Secretary for Agriculture, Industry, and Commerce, has offered a prize of 3,000 lire (about $115 l$.) for the best monograph on the cultivation, growth, and diseases of the species citrus (the common lemon-tree). The competition will last until May, 188I, and all particulars may be learnt direct from the Secretary's office at Rome.

A VERY satisfactory Report comes to us from the Free Library Committee of Dundee. Under the care of Mr. Maclachlan, the library, in the quality of its contents and its organisation, is becoming one of the first of the kind in the kingdom, and is evidently well appreciated by the basy and inquisitive workers of Dundee. Scientific works have a large share of attention, and the museum, we are glad to see, is rapidly extending, and is likely ere long to be worthy of one of our great commercial centres. We have received a carefully compiled fourth supplement to the catalogue of the Library.

THE additions to the Zoological Society's Gardens during the past week include two Slender Loris (Loris gracilis) from Ceylon, presented by $\mathrm{Mr}$. Leith Bonhâte; a Common Rhea (Rhea americana) from South America, presented by Major Venables; a Purple-crested Touracou (Corythaix porphyreolopha) from East Africa, presented by the Rev. J. A. Gould; a Geoffroy's Dove (Peristera geoffroii), bred in the Gardens.

\section{OXYGEN IN THE SUN}

$T$ HE paper referred to appeared in the October number of this Journal. ${ }^{2}$ A cursory glance at it gives the impres. sion that the methods had been carefully criticised beforehand, that the experiments had been made with minute accuracy and that the results were trustworthy ; but closer examination of it raises most serious questions on all the points mentioned. Errors of method and of experiment appear which make it quite impossible to accept the conclusions reached. It is the purpose of this note to point out some of these.

In the first place the author throughout the paper confounds Angström's scale numbers with wave-lengths. Thus, for example, p. 257 , he says, line 18 , the photographs were " in sections of eighty to one hundred wave-lengths," line 24, "each wave-length being five millimeters in extent," and line 34 , "each section of one hundred or more wave-lengths;" p. 258 , line 24, "Error amounting to half a wave-length could therefore exist in the position of a line, according as it fell on one side or the other of a figure on the scale expressing a wavelength;" p. 259 , line 18 , one iron line "to every eleven wavelengths was used;" p. $26 \mathrm{r}$, line 18 , no element gives "a line within two or three-tenths of a wave-length of that position;" p. 264, line 16, "no other element furnishes a line which falls on the same wave-length." In proof that he really means scale divisions, he gives a section of his chart on p. 259, and says, line 38 , "On the first space below the line is the scale of wavelengths, each wave-length being five millimeters in extent ; " and p. 260 , line 28 , "in the eighteen wave-Iengths represented in the diagram." There are eighteen scale divisions in the diagram, each scale division being five millimeters long. Again, p. 264, referring to the coincidence of oxygen and solar lines in his table, he says, line 2 , " in four, the difference is only five onehundredths of a wave-length; in twenty-two, ten one-hundredths of a wave-length; in four, fifteen one-hundredths of a waveof a wave-length; in four, fifteen one-hundredth a wave-length; and in the remainder, the greatest difference is only thirty-five one-hundredths of a wave-length." Referring to the table, the four lines first mentioned are given as $39^{\circ} 82^{\circ} 75,4075^{\circ} 50,4345^{\circ}{ }^{\circ} 5$, and 4483.80 ; the corresponding oxygen lines being given as $3982^{\circ} 70,4075^{\circ} 45,4345^{\circ} 20$, and $44^{8} 3^{\circ} 75$. The difference is obviously five one-hundredths of a scale division, not of a wave-

I Note on J. C. Draper's paper "On the Presence of Dark Lines in the Solar Spectrum which correspond closely to the Lines of the Spectrum of Oxygen. From the

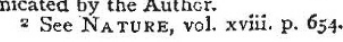


length. From the fact that this error runs through the entire paper, it would almost seem as if the author was not aware of the distinction between wave-lengths and scale numbers. Using Ångströn's scale he confuses wave-lengths with ten millionths of a millimeter; whereas in the case of $D$ for example, the wave-length is nearly 6,000 times greater. If the author really means what he says, he asserts that the wave-length of the mean ray of the spectrum is one two-hundred and fifty-millionth of an inch instead of about one forty-thousandth, as we know it is.

Second, the author deems it of the greatest importance in the preparation of his solar photographs to use reflected rays exclusively; saying, p. 256, last line, "at no time did the solar rays pass through glass; all error that might arise during refraction was thus avoided." After this virtual condemnation of the use of refraction at all, he not only uses for comparison Ångström's wave-lengths made with achromatic lenses and a refracting grating, constructing even his chart upon them as a basis, p. 258 , line 7 , "the values assigned fo the ,wave-lengths in this chart are those of Ångström "; but the very spectrum of oxygen by which the coincidence of the lines of this element with those of the sun spectrum were to be established, was photographed with glass prisms and achromatic lenses.

Third, the author states that the prisms with which the spectrum of oxygen was photographed were adjusted "to the minimum deviation of $\mathrm{D}^{\prime}$." Supposing $\mathrm{D}_{1}$ to be meant, this precaution, which gives the appearance of extraordinary accuracy to the adjustment, is practically an impossibility with the apparatus employed. Minimum deviation of the $\mathrm{D}$ line as a whole could not under these circumstances be distinguished from that of either of its components, nor could that of $D_{1}$ be distinguished from that of $\mathrm{D}_{2}$. Moreover, it is difficult to understand why he adjusts to minimum deviation for $D^{\prime}$ and not for $G$, near which the work is to be done. Instead of $D^{\prime}$, the line for which his apparatus was adjusted should have been chosen in the photographic portion of the spectrum, for example between $\mathrm{G}$ and $\mathrm{H}$.

Fourth, on page 265 , line 25 , the author says that this "is a problem not to be solved by the comparison of two spectra of small dispersion." Hence it is a matter of some surprise to find that in getting his oxygen spectrum, he uses only "two flint glass prisms of 60," and for objectives, " achromatics of ten inches focus." The bright line spectrum of oxygen taken by Henry Draper, which the author in this paper inferentially attacks; was made, as we find on examination, with a direct vision battery of nine prisms and an observing telescope of forty. two inches focal length. The original negatives taken with the latter apparatus must consequently have been eight or nine times as long as the author's; and even these were none too large for the proper solution of the question.

Fifth, the author seems to have attempted to compate together a diffraction spectrum of the sun with a prismatic spectrum of oxygen. Such a comparison, by the method adopted, is manifestly of no value. Owing to the irrationality of dispersion of various refractive media it is an extremely difficult thing to compare accurately two prismatic spectra of different kinds. But the matter rises to an absurdity when a comparison is attempted between a grating spectrum and a prism spectrum. The graphic method, employed to supplement the direct method, does not appear to help the comparison, since the author nowhere gives both co-ordinates to the curve constructed.

Sixth, it is more than questionable whether the measurements of the solar lines actually made by the author are capable of the accuracy he assigns to them. The values in his table of wavelengths are given to one hundredth of a division of Angström's scale. As the author says on p. 257 that each division of this scale, which is one millimeter, was enlarged to five millimeters upon the paper scale on which the photographs were projected, to measure to one hundredth of a scale-division would require the measurements on the screen to be made to one-twentieth of a millimeter or the one five-hundredth of an inch, about ; a degree of refinement highly improbable under these conditions. Moreover the accuracy of the results of such measurements is seriously impaired by the variation in the position of the lines on the screen, due to the fact that the large number of negatives (eight or nine apparently), required to give the whole photographic spectrum, must, unless special precaution was taken (of which there is no evidence), have been made with glass of different thicknesses. When projected in the lantern, this variation in thickness would necessitate a change in focus and so cause a change in the magnifying power. The smaller sizes of photographic glass vary in thickness from one to two millimeters.
Consequently the displacement of the lines due to the difference of magnifying power arising from this cause would exceed considerably the limit of measurement, which, as above stated, was the one five-hundredth of an inch. But another and a more serious cause of inaccuracy must here be pointed out. From the data given by the author, it may readily be calculated that his original photographs of the oxygen spectrum, taken with two prisms of $60^{\circ}$ and with lenses of ten inches focus, could not have been over half an inch long in the region from $G$ to $H$. Since Ångström's chart from G to H is sixteen inches long, the author's spectrum would have to be magnified thirty-two times to make it the size of this. But as each millimeter of Ångström's scale was made five millimeters on the author's scale of measurement, the original negative as thrown on the screen must have been magnified one hundred and sixty diameters. Any one who has worked at all in spectrum photography, knows that it is utterly futile for purposes of measurement to magnify a photograph taken under these circumstances, as much as this, since then the size of the silver grains becomes larger than the details of the picture. In the absence of any precise statement the reader has to make the calculation for himself; but the figures above given cannot be far astray.

Seventh, there is only an appearance of accuracy when the attempt is made to fix the position of the oxygen spectrum lines to hundredths of one of Angström's scale divisions. The projection method by which his solar lines were measured, has already been proved inadequate. And as to the method of graphical interpolation, used as auxiliary to the lantern, it does not appear that, as used by the author, it was capable of any such accuracy as that claimed. In constructing the curve, the iron lines are taken with Ångström's values for the wavelengths; but these, though estimated to tenths, were read only to whole divisions of the scale. Moreover, only forty-seven iron lines were used in all, or one to every eleven scale divisions ; the reading being to one one-hundredth of a scale division, or $\mathrm{I}, 100$ numbers to one iron line. Since the author measured no wave-lengths directly, he was obliged to construct a considerable "portion of the curve from the wave-lengths of oxygen and air lines already given by various authorities." These values were taken, p. 258, from Watt's "Index of Spectra." On referring: to this book, the values are given only to the units place." And even then, discrepancies amounting to from three to five entire units, or from three hundred to five hundred times the author' limit, appear in the wave-length as given by the various authors relied on for the measurements employed in the paper before ns.

Eighth, the author nowhere states the peculiar character of the lines in the oxygen spectrum and appears not to know that they have any. He has apparently taken it for granted that the lines of oxygen are intrinsically as sharp as the lines of the solar spectrum. But this, at least in many instances, is known not to be the case. Consequently it is quite impossible to measure the oxygen lines as accurately as the solar lines, and even these, as has been shown, cannot be measured to the accuracy which the author claims. Angström himself admits that there may be an error of one-tenth of a division in his scale numbers.

It would seem sufficiently obvious from what has been said that the results given in this paper are entirely vitiated by the errors of method and of experiment which it contains. The author must not be confounded, because of the similarity of initials, with the distinguished investigator, Dr. J. W. Draper.

\section{UNIVERSTTY AND EDUCATIONAL INTELLIGENCE}

UNIVERSITX education for women may be taken as firmly established in England. The names of nine out of eleven female candidates have just been posted at Burlington Gardens as having passed the winter matriculation examination of the University of London, half-a-dozen in the honours division, besides three more in that next below, and are thus now on the high road to its B.A. degree, on the occasion of its first decorating their sex three academical years hence. From two interesting articles in the Daily Neces it is seen that Girton and Newnham Colleges have attained to unexpected success. The former is so much too small for the number of students that yearly flock to it that it is to be nearly doubled in size. At both institutions the students work much more earnestly than the average student of the hitherto privileged $\mathrm{sex}$, and the examinations passed, at least at Girton, would 